\title{
La estadística y el curso de la razón pública: compromiso e imparcialidad en un mundo cuantificado*
}

\author{
THEOdORE M. Porter \\ UCLA \\ tporter@history.ucla.edu
}

Recibido: 03.04.2009

Aceptado: 02.11.2009

\begin{abstract}
¿Dónde podemos encontrar la razón en la actualidad? Max Weber interpretaba la racionalidad casi como un sinónimo de modernidad. Pensaba que su ascenso en el mundo occidental estaba ligado a la expansión del capitalismo, aunque iba más allá de las instituciones específicamente lucrativas llegando hasta las instituciones políticas. La racionalización burocrática era para él casi una tautología, e incluso cabría decir que una teleología, a pesar de su terrible ambivalencia sobre las tendencias del desarrollo histórico. También fue responsable de considerar la centralidad de la razón en la ciencia como algo autoevidente. Weber resulta especialmente pertinente para el tema que abordamos aquí porque no confinaba la racionalidad científica a los cuerpos de conocimiento considerados rigurosos e imparciales como la física, sino que exploró su emergencia en los mundos más cotidianos del comercio o la contabilidad. También podemos añadir la estadística sin distorsionar las ideas de Weber.

Aunque en este proceso de racionalización, Weber identificó fuentes de religión irracional, su legado incluye la asunción generalizada de que tal proceso avanza inexorablemente de forma más o menos autónoma. La percepción que Weber tenía de su fuerza fue aceptada tanto por los científicos sociales, que la celebraron, especialmente en América, como por los críticos culturales que la despreciaron. Para Max Horkheimer y Theodor Adorno, sin embargo, la racionalización no era tanto el triunfo de la razón como su encierro, (la jaula de hierro) como el castigo a la belleza, al asombro y al júbilo espontáneo. Jürgen Habermas, aunque de forma más sutil, también se enmarcó en la tradición de la Escuela de Frankfurt, y a la vez que asumía el incesante poder de la racionali-
\end{abstract}

\footnotetext{
* Traducción de Lino Camprubí y Beatriz Mañas. Revisión de José M. Arribas
} 
zación weberiana, intentó trazar una forma diferente de razón, producto de la comunicación más que del aislamiento y de la opresión. Su Öffentlichkeit, la esfera pública, encarna esa ambición y, sin embargo, la trayectoria que entrevió para ella alguien como Habermas deja poco lugar a la esperanza. El capitalismo emergente había creado un espacio de discusión y debate en los periódicos y cafés, que sería clausurado por la sociedad de masas en una fase posterior del desarrollo económico y social, dejando atrás el mundo que funcionaba según la lógica del cálculo weberiano. La contabilidad y la estadística, como veremos, no deben considerarse extrañas a la acción comunicativa o a la esfera pública, pero surgen de impulsos diferentes y, a menudo, contradictorios (Horkheimer y Adorno [1944] 1972; Habermas [1962] 1989).

¿Sería pedir demasiado a la estadística, o a cualquier otra forma de conocimiento, que hiciera posible la fundación de la esfera pública como el lugar de la razón accesible a todos los ciudadanos? Si en lugar de ello adoptamos un estándar menos rígido, podemos comprobar cómo la estadística se ha hecho omnipresente en la circulación del conocimiento, la información y la opinión. Sin embargo, la categoría «estadística» cubre un amplio abanico de formas de conocimiento. Por un lado, tenemos los números como información , y como señala Yaron Ezrahi, hacen referencia a algo más superficial, con menos necesidad de análisis o interpretación que lo que denominamos «ciencia»o, incluso, «conocimiento» (Ezrahi 2002). Desde esta perspectiva se presupone que la información es transparente y no-problemática, apta para ser usada autónomamente casi por cualquiera. Es mejor no hacer preguntas porque «cualquiera» comenzará a sospechar si se le alerta de todas las selecciones y manipulaciones estandarizadas o ad hoc, que figuran en la definición que ha hecho posible la obtención de esos números; y más aún si se consideran los modos en los que los grupos de interés y de presión pueden amenazar, inducir y sobornar para introducir sus números preferidos en la primera plana de los medios de comunicación de masas. Casi por definición, esa información idealizada no cuestiona los orígenes, pero contempla los datos como si fueran hamburguesas, meros objetos de consumo. Por otro lado, existen bibliotecas enteras dedicadas a las metodologías de medición y al análisis estadístico en las ciencias naturales y sociales. También en este caso los números circulan como información, sin someterse a escrutinio crítico, pero tales intercambios se suelen hacer bajo la presunción de que los números han sido producidos de forma competente, y han sido analizados por críticos expertos antes de salir a la luz. La inferencia y la medición estadística son consideradas como la forma de conocimiento más elevada a la que pueden aspirar los seres humanos, especialmente en el caso de las ciencias sociales. La estadística moderna ha recibido muchas críticas y no sólo por razones internas, también por haber estrechado inapropiadamente el campo de la investigación social o haber silenciado la discusión pública apelando al rigor de lo cuantitativo.

No obstante, en la estadística, los modos experto y popular van de la mano. Los científicos también pueden ser crédulos, especialmente respecto a los números, a la vez que la discusión del público no experto puede desafiar, y a me-

EMPIRIA. Revista de Metodología de Ciencias Sociales. N. ${ }^{\circ}$ 18, julio-diciembre, 2009, pp. 19-35. ISSN: 1139-5737 
nudo con eficacia, las afirmaciones estadísticas. La religión de la ciencia no es realmente monoteísta si toda clase de números se aceptan acríticamente como información. Los escépticos de la razón democrática se quejan de que el público se apoya en la estadística como los borrachos en las farolas, más para no caerse que para ver con claridad, pero olvidan que los propios científicos y expertos descartan cualquier evaluación de un proceso de medición que vaya más allá de los detalles para criticar sistemas enteros de cálculo, insistiendo en que lo propio de un participante serio en la discusión es llegar a mejores estadísticas. El fundador de la disciplina estadística, Karl Pearson, respondió a las dudas sobre sus cálculos con el siguiente desafío: «Estadísticas sobre la mesa, por favor» ${ }^{1}$.

En la actualidad, existen poderosas fuerzas institucionales que trabajan para dibujar una línea divisoria entre la discusión experta y la discusión pública. En estos tiempos se nos anima a pensar que la ciencia se encuentra casi por naturaleza separada de las preocupaciones mundanas, y a menudo corruptas, de los actores políticos o incluso de los ciudadanos ordinarios. Decimos que la ciencia es técnica, una palabra que ha venido a significar la competencia especializada que se requiere para producirla, así como las comunidades cerradas que poseen dicha competencia. Aunque el sentido original del término técnico se refiere a los secretos comerciales y a las habilidades artesanales, se utiliza hoy día para ser aplicada paradigmáticamente a los métodos matemáticos de la ciencia. En las últimas décadas, la ciencia no sólo acepta, sino que incluso se jacta de su aislamiento del público como un fundamento necesario de la objetividad. La estadística matemática fue el medio más efectivo por el que las ciencias sociales pudieron transformarse en «técnicas» en este sentido. La nueva ciencia social consideró la estadística como una forma de manipular a un público irracional, más que como un modo de instruirlo. Aunque la élite científica siempre ha sido escéptica sobre la inteligencia de la gente común, existe un contraste importante con respecto a los ideales ilustrados de conocimiento público. En aquellas campañas para instruir al público que surgieron en el siglo XVIII, y que florecieron como nunca en el XIX, la estadística fue propuesta, con un espíritu casi utópico, como el fundamento indispensable del conocimiento público, de la razón en la esfera pública. Ese sueño ha perdurado hasta el siglo XX, aunque cada vez parece menos natural (Porter 2009).

A finales del pasado siglo los científicos sociales eran extremadamente dependientes de los números oficiales, a pesar de contemplar la estadística descriptiva como el simple resultado de procesos de registro burocráticos y no como una ciencia seria. La ciencia social de postguerra estuvo muy interesada en asignar números a objetos que no podían medirse directamente, o cuya existencia apenas se había reconocido hasta entonces, tales como las actitudes colectivas, los ciclos económicos, la personalidad autoritaria, la inteligencia biológica, y la pendiente de las curvas de indiferencia. $\mathrm{O}$ bien, trabajó para acabar con la

1 Ver Stigler, Stephen M. (1999): Statistics on the Table: The History of Statistical Concepts and Methods (Cambridge: Harvard University Press).

EMPIRIA. Revista de Metodología de Ciencias Sociales. N. ${ }^{\circ}$ 18, julio-diciembre, 2009, pp. 19-35. ISSN: 1139-5737 
variabilidad de las series estadísticas del crimen, las diferencias salariales o las tasas de nacimiento, y para medir posibles causas. En todo caso, el análisis estadístico pasó a considerarse como el fundamento apropiado de la inferencia en las décadas de 1920 y 1930, y se institucionalizó rápidamente en libros de texto y revistas (Gigerenzer 1989). Los métodos de análisis se apoyaron en una matemática sofisticada que no estaba hecha para audiencias populares. Los sociólogos y politólogos no se enfrentaron directamente a estos métodos de análisis, por el contrario, las nuevas herramientas trajeron conceptos novedosos que implicaban medir y aislar la variabilidad. La desaparición de categorías de estudio social podría haber parecido trágica, pero los científicos sociales son admirablemente estoicos y, de hecho, buscaron metodologías y conceptos lejanos como distintivo del científico respetable. Admiradores y críticos de la nueva ciencia social señalan que, al retirarse de la esfera pública y enfatizar las matemáticas, los científicos sociales estaban siguiendo el trillado camino de las ciencias naturales «duras», pero esta afirmación es profundamente engañosa. Las ciencias sociales del siglo XX solidificaron, si no se puede decir que inventaron, la idea de que la verdadera ciencia se distingue por su carácter técnico, y de que la introducción o apropiación consciente de herramientas y conceptos técnicos es el camino real hacia el estatus científico. Sociólogos de postguerra, politólogos y economistas, desarrollaron una teoría global de la «modernización» histórica que convirtió a la ciencia social misma en clave protagonista de la historia de la modernidad. Ellos definieron la modernización como el surgimiento de sociedades complejas e interdependientes, un mundo nuevo y desconocido que no podía ser captado por conceptos vernáculos. La simple observación y escucha de lo que ocurre alrededor no basta para tener acceso a las causas complejas y remotas. El conocimiento social real requería expertos disciplinados. Los teóricos de la modernización señalaron que la ciencia y la medicina habían sido profesionalizadas con éxito, y se adjudicaban la tarea de hacer lo propio con las ciencias sociales. Al igual que Weber, e invocando a Weber, veían la racionalidad burocrática y científica barriendo el mundo, pero no compartían su pesar ante semejante evidencia ${ }^{2}$.

La ciencia social, en su forma técnica, ha idealizado la profesión científica como una comunidad cerrada que entrena a sus propios miembros y establece sus propios estándares. Pero la ciencia social reconoce, y así lo requiere la idea de modernización, que el conocimiento contribuye al buen gobierno. ¿Cuánto debe difundirse la ciencia para conseguirlo? Los científicos sociales de postguerra fueron especialmente escépticos ante la democracia (Haney, 2008), creyendo que los votantes actúan sabiamente sólo si respaldan los resultados de la investigación experta. Ilustrar al público, en el sentido de proporcionarle el conocimiento necesario para evaluar las cuestiones por sí mismo, no parecía prometedor ni necesario. Las ciencias sociales cultivaron otro tipo de audiencia, a

2 Haskell (1977) documenta el surgimiento de esta perspectiva en Estados Unidos alrededor de 1900, y la usa para apoyar una explicación funcionalista de los cambios en las ciencias sociales.

EMPIRIA. Revista de Metodología de Ciencias Sociales. N. ${ }^{\circ}$ 18, julio-diciembre, 2009, pp. 19-35. ISSN: $1139-5737$ 
saber, aquéllos con poder de decisión en las burocracias supuestamente racionales que habían ascendido en el gobierno y los negocios.

Esta alianza entre matemáticas y administración recuerda a la ciencia estadística del siglo XVIII, que los contemporáneos denominaban aritmética política o cálculo de probabilidades. Alexis de Tocqueville describía el Antiguo Régimen francés según un proceso de creciente centralización que la Revolución no habría detenido, sino acelerado; pues bien, el estado francés del siglo XVIII valoraba la estadística y, como la mayoría de las monarquías continentales, era reticente a publicar sus números. En las décadas anteriores a la Revolución, el gobierno de Luis XVI se esforzó decididamente por preparar un censo y organizar los registros de nacimiento. Los matemáticos, sobre todo Pierre Simon Laplace, llevaron a cabo cálculos de probabilidad para estimar la población francesa a partir de las estadísticas de nacimientos, e incluso ofrecieron cifras sobre los márgenes de error. El matemático Daniel Bernoulli publicó un modelo matemático sobre el crecimiento de la población asociado a la inoculación contra la viruela. Eric Brian (1994) describe cómo la alianza entre matemáticos y administradores promovía el uso de métodos avanzados de probabilidad para seguir la evolución de las poblaciones (Brian 1994; Daston 1988; Rusnock 2002).

El filósofo Condorcet resulta especialmente interesante para estas cuestiones, pues estaba fuertemente comprometido con el uso de las matemáticas y los números para definir las condiciones de la implicación ciudadana en las decisiones políticas. Su ideal de un mundo cuantificado se ejemplifica bien en su vigoroso apoyo al sistema métrico. Un sistema uniforme de pesos, medidas, catastros y moneda capacitaría a cualquiera, incluso aunque tuviera una rudimentaria instrucción en aritmética, para ser autosuficiente en el cálculo y, por tanto, para cuidar de sus propios intereses (Alder 2002; Gillispie 2004). Otro gran defensor democrático de este ideal de medida fue Thomas Jefferson. Condorcet dedicó su carrera matemática a desarrollar las probabilidades de las elecciones y las decisiones judiciales, de forma que permitieran revelar la voluntad general con un margen de error aceptable. Pero, ¿podía cualquier persona utilizar la matemática de Condorcet y determinar por sí misma si el sistema electoral era limpio? En realidad no, y Condorcet nunca intentó dirigirse al público de esa forma. Más bien, a pesar de su compromiso con un gobierno al servicio del pueblo, dedicó la mayor parte de su trabajo, incluyendo muchos de sus escritos matemáticos, a la Corona y, en la práctica, al alto funcionariado. El propio programa matemático, cuyo objetivo era sustituir el juicio falible por el cálculo racional, puso de manifiesto sus dudas acerca de la racionalidad pública (Baker 1975; Gillispie 1980; Brian 1994).

La Revolución Francesa, la mayor de las «revoluciones democráticas» de finales del siglo XVIII, intensificó el temor de las élites a que las masas pudieran gobernarse a sí mismas. Las instituciones estadísticas, estimuladas no sólo en Francia por la Revolución, fueron diseñadas para proporcionar información al Estado más que para constituir una base del gobierno liberal. La proliferación de censos alrededor del año 1800 fue sobre todo una reacción a la guerra y a la ne-

EMPIRIA. Revista de Metodología de Ciencias Sociales. N. ${ }^{0}$ 18, julio-diciembre, 2009, pp. 19-35. ISSN: 1139-5737 
cesidad de datos precisos para el reclutamiento militar y el suministro de fuerzas militares. Desde luego, las instituciones liberales no fueron democráticas al comienzo, después de todo, el derecho al voto estuvo restringido durante la mayor parte del siglo XIX a los varones razonablemente prósperos y educados. Las clases populares tenían más posibilidades de ser objeto de investigaciones estadísticas, que de ser sus usuarios. Pero el liberalismo sí postulaba que los éxitos y fracasos del gobierno debían hacerse públicos y dejar de ser secretos al acceso tan solo de una casta privilegiada. Casi todo el mundo estaba de acuerdo en que la recolección y publicación de cifras era vital, tanto para desarrollar una opinión pública informada, como para guiar las decisiones gubernamentales.

De hecho, el prosaico campo de la racionalización burocrática fue la sede de ambiciones radicales y misionarias. En la Tercera República Francesa, Alfred de Foville hizo de la estadística un instrumento esencial del buen gobierno. ¡Aux armes, citoyens, que los números son armas de una batalla eterna! «Allá donde haya una lucha entre los defensores del interés general y los defensores del interés privado, nos encontraréis (a los estadísticos) en nuestros puesto preparados para la marcha». En la América Progresista, Carroll Wright, del Bureau of Labor Statistics de Massachusetts (al que debemos la medida y, en cierto modo, la idea misma de desempleo), habló de la estadística precisa como un deber sagrado. Tenía la esperanza de que los números, más que la lucha de clases, harían posible la mejora de la vida entre los trabajadores (Porter 1995; Topalov 1994; Stapleford 2009). Las oficinas de estadística de Berlín, Viena y otras ciudades - no sólo las capitales - comenzaron a publicar, tanto revistas populares de estadística, como compilaciones numéricas oficiales. Pensaban que una ciudadanía informada debería estar familiarizada con las estadísticas. Y en los años treinta y cuarenta, los americanos pioneros en la investigación de la opinión pública, defendieron, siempre en un tono que reflejaba lo sublime de su programa, el argumento opuesto de que las medidas de la opinión permitían a los cargos electos calcular el sentir popular y actuar de acuerdo con los deseos de la gente (Igo 2007).

Desde aproximadamente 1820 hasta el año 1880, la estadística era sinónimo de ciencia social, y en aquellos años no era ninguna «torre de marfil». La estadística, es decir, la estadística social, se ponía en práctica en las universidades, especialmente en naciones como Alemania donde el profesor era un funcionario y donde la política económica competía con el derecho en la formación de aquellos funcionarios estatales que parecían haber inspirado a Weber la extraña idea de que la burocracia es la sede la racionalidad. Disciplinas como la Staatswissenschaften (ciencias del Estado) dieron cuerpo institucional al ideal de que la educación debía ponerse al servicio de la política. Los directores de oficinas estadísticas ocupaban a menudo cargos universitarios o impartían seminarios; el caso más famoso fue el de Ernst Engel quien, primero en Sajonia y después en Prusia, formó a toda una generación alemana de economistas de la historia (Lindenfeld 1997; Labbé 2007). Más hacia el oeste, en Francia, Inglaterra y Norteamérica, la sede principal de las ciencias sociales fueron las sociedades vo-

EMPIRIA. Revista de Metodología de Ciencias Sociales. N. ${ }^{\circ}$ 18, julio-diciembre, 2009, pp. 19-35. ISSN: 1139-5737 
luntarias: la Statistical Society of London constituyó, de alguna manera, el prototipo de las instituciones de la ciencia social.

Con esto quiero señalar que gran parte de la ciencia social del siglo XIX era empírica, sobre todo estadística, y que no estaba separada ni social ni intelectualmente de la esfera pública. Ahora bien, las ciencias sociales no eran lo único que se podían producir y debatir en el dominio público. Los movimientos populares también recogían, adaptaban y reinterpretaban las elucubraciones teóricas de un David Ricardo o un Karl Marx (Porter 2003). La mayor parte de la economía política del siglo XIX era también empírica y estadística, algo bien sabido para el caso alemán, donde la «escuela histórica» era todavía más una escuela de estadística, pero un vistazo al Economic Journal inglés, al American Economic Review o al Journal of Political Economy nos muestra que, todavía en 1900 la mayoría de los artículos trataban de la producción, el comercio o los movimientos obreros desde un punto de vista estadístico, político o institucional. Normalmente discutían problemas políticos que interesaban a un público amplio y - esto es lo más importante- la estadística fomentaba el compromiso público en lugar de obstruirlo. Uno de los factores que facilitaban la comprensión del público era que los números se referían normalmente a cosas que se podían contar, como gastos monetarios, personas desempleadas, muertes por cólera o suicidio, condenas por robo, o acres sembrados de trigo o centeno. En tales circunstancias es fácil comparar números diferentes referidos a la misma cosa, para ver cuál es mayor o para detectar tendencias.

Además, no se requerían operaciones matemáticas sofisticadas. El siglo XIX, el siglo de la burguesía, prefería cuentas cerradas a estimaciones probabilísticas. Es verdad que la organización requerida para cuadrar la población nacional es tan problemática y tan vulnerable a la manipulación como cualquier procedimiento estadístico para estimar la magnitud de un coeficiente o para calcular el error, pero la enumeración completa era el «patrón-oro» de la estadística, sobre todo porque procedía de experiencias conocidas por todos y se podía analizar con operaciones aritméticas básicas. El muestreo casi no se usó en las estadísticas públicas antes de finales del siglo XIX (Desrosières 1992).

A pesar de los argumentos de un importante estudio que presenta los últimos años del siglo XIX como la cúspide de la objetividad auto-negadora en la producción de imágenes científicas (Daston y Galison 2007), no encuentro en las estadísticas de esos años casi nada de lo que la ciencia social reciente define como objetividad. De hecho, esta puede ser la razón de que el período anterior a 1880 sea normalmente considerado como prehistoria de la ciencia social, y no propiamente como historia. No podemos decir que a aquellos estadísticos no les importara la objetividad, pero la palabra fue poco usada antes de 1880 . Ellos deseaban alcanzar un conocimiento sólido y aspiraban a una imparcialidad libre de prejuicios e intereses personales, por lo que sería más acertado decir que tenían una noción de los requerimientos de la objetividad diferente a la que existe a partir del siglo XX. Me gustaría subrayar dos diferencias respecto a la ciencia social de nuestros días.

EMPIRIA. Revista de Metodología de Ciencias Sociales. N. ${ }^{\circ}$ 18, julio-diciembre, 2009, pp. 19-35. ISSN: 1139-5737 
En primer lugar, los investigadores de la época victoriana no se distinguían precisamente por el cuidado en evitar mezclar los juicios de valor con los análisis e incluso con las cuentas. Puede servirnos de ejemplo la famosa investigación de Charles Booth sobre Londres, en la que no se vacilaba en aplicar a sus sujetos de estudio calificativos como perezosos, degradados, criminales o degenerados y en ella se clasificaba a todo un sector de la población como «residuo.» (Himmelfarb,1991), y cualquiera que haya hojeado un escrito de Marx, sabe que los juicios morales no eran exclusivos de la ciencia social burguesa. En segundo lugar, los científicos sociales no consideraban que la ciencia tuviera que producirse desde una posición neutral. El mejor ejemplo que he encontrado es el del francés Frédéric Le Play, que llegó a considerar que el lugar donde había que buscar las respuestas a las preguntas sociales eran las élites (tradicionales), pues éstas conocían a sus arrendatarios y empleados personalmente. El propio Le Play no pertenecía a los grupos que estudiaba (ganaderos siberianos, mineros noruegos, etc.) $\mathrm{y}$, por tanto, podía haber alegado distancia e independencia si hubiese pensado que así afianzaba su credibilidad, pero no lo hizo; es más, consultaba a líderes locales para que le señalaran las familias relevantes y aprender de ellas, abusando de sus consejos a la hora de elaborar las conclusiones. Para Le Play, las funciones del investigador social debían incluir las de señor o protector (patron) (Porter 2011).

Muchos de los colaboradores de la London Statistical Society eran funcionarios públicos, a menudo estadísticos, que trabajaban en la junta de comercio (George Richardson, Porter) o en la oficina del censo (William Farr). No obstante, a pesar de su pose de neutralidad política, recogida en una resolución para limitar sus discusiones a hechos que pudieran ser «cribados por otros [aliis exterendum]», eran ciudadanos activos en el fomento de la salud pública, de seguros de vida para los pobres, o de políticas de comercio y de trabajo infantil. La Manchester Statistical Society se nutría de reformadores urbanos, y los famosos Congresos Internacionales de Estadística de Quetelet que comenzaron en 1851, eran territorio de altos mandos del gobierno. Un caso aún más extremo, aunque giraba menos en torno a la estadística, es el de la Social Science Association, a la que, durante la segunda mitad del siglo diecinueve, acudían duques, presidentes y obispos, hombres políticamente comprometidos que, a veces, detentaban autoridad sobre las poblaciones que investigaban (Hilts 1978; Goldman 2002). Alrededor de 1940, la idea misma de las ciencias sociales parecía excluir ya el conocimiento práctico de políticos y empresarios forjados en juntas de gobierno, fábricas o movimientos de reforma. Para Le Play, en cambio, la participación práctica en asuntos públicos era una ventaja o, incluso, una necesidad para la práctica de las ciencias sociales. Tener responsabilidades, razonaban, otorgaba tanto la capacidad como la obligación moral de observar (y, a menudo, cuantificar) a la sociedad, y poder así actuar con conocimiento de causa.

Durante el siglo diecinueve muchos asuntos sociales y de discusión pública estaban ligados a la estadística, o incluso emanaban de ella. Los mapas estadísticos sombreados de la década de 1820 trazaban la línea entre la Francia educa-

EMPIRIA. Revista de Metodología de Ciencias Sociales. N. ${ }^{\circ}$ 18, julio-diciembre, 2009, pp. 19-35. ISSN: 1139-5737 
da y la analfabeta, desde Ginebra hasta Saint Malo. En 1851, un nuevo censo corroboraba el anuncio de que Gran Bretaña se había transformado en una sociedad urbana, y el censo norteamericano de 1890 fue la base de la célebre declaración del cierre de la frontera, que inspiró la tesis epónima del historiador Frederick Jackson Turner sobre el papel de la frontera en la historia de EEUU. El recuento británico de 1851, el primero en tener en cuenta afiliaciones y prácticas religiosas, produjo tal inquietud acerca del debilitamiento de la fe y del peso relativo de la Iglesia de Inglaterra, que no se volvió a repetir un censo semejante. La estadística, en suma, ayudaba a comprender qué significaba ser inglés, norteamericano, francés, prusiano, o italiano (Anderson 1988; Palsky 1996; Patriarca 1996).

Aunque los problemas de identidad y pertenencia eran importantes, sobre todo para la estadística nacional, las ciencias sociales trataban, ante todo, de problemas sociales. En un mundo crecientemente urbanizado e industrializado, se iba perdiendo el contacto entre las clases y escaseaba el paternalismo idealizado por Le Play; la estadística vino a llenar ese vacío, ofreciendo un panorama más amplio y distante de una población crecientemente anónima. Era más fácil agrupar a los trabajadores o a los pobres y referirse a ellos como «brazos», o como ignorantes y volubles, o como masas. Los estudios estadísticos servían para trazar el desarrollo de epidemias de cólera o delimitar centros de ignorancia y robo, la mirada estadística se dirigía a menudo hacia instituciones como hospitales, asilos, escuelas y ejércitos, y las conclusiones que arrojaban no eran muy halagadoras. La obsesión por la degeneración social, generalizada a finales del diecinueve, estaba tan saturada de estadística como lo estaban las campañas eugenésicas y sanitarias destinadas a combatirla. Y en este empeño participaban distintos profesionales y reformadores, incluyendo médicos, empresarios, socialistas, líderes políticos, directores de manicomios, economistas, biólogos y expertos en estadística. Sus discusiones tenían lugar en reuniones de sociedades profesionales, conferencias públicas y periódicos, así como en revistas médicas y académicas. Aunque, desde luego, la mayor parte de la gente no podía hacerse oír, estos debates pertenecían al público (Wolfenstein 2004; Pick 1989; Szereter1996).

Pero, ya desde el principio del siglo XX, la discusión comenzó a cambiar a medida que creció la insistencia en la preponderancia de saberes más especializados. Los científicos sociales no procuraron clausurar o ignorar la discusión pública, al menos al principio, pero si esperaban que se reconociese su autoridad en materia política, legitimado ahora por la ciencia y capaz de reconocer el funcionamiento del mundo independientemente de los deseos de la mayoría. ¿Cómo habría de constituirse la esfera pública en la era de la ciencia? ¿Sería suficiente con promover la discusión crítica y libre, al modo de John Stuart Mill en On Liberty, o debería investirse a los expertos con el poder necesario para monopolizar los debates sociales?

La pregunta tiene especial relevancia en relación con Karl Pearson, tal vez el mayor artífice de la transformación de la estadística en un campo matemático

EMPIRIA. Revista de Metodología de Ciencias Sociales. N. ${ }^{\circ}$ 18, julio-diciembre, 2009, pp. 19-35. ISSN: 1139-5737 
(Porter 2004). Pearson desarrolló el cuerpo de su trabajo matemático entre 1890 y 1914 aproximadamente, la misma época en la que estaba perfilando el lugar que había de ocupar la estadística entre las ciencias y en relación con el Estado, pero es también conocido por sostener que muchos asuntos políticos (como qué hacer respecto al alcoholismo entre los hijos de los afectados) son, ante todo, científicos y, por tanto, deben depender de investigaciones competentes antes que de la opinión del hombre de la calle. En este sentido hay que entender que dedicara los últimos cuarenta y cinco años de su vida a obtener métodos matemáticos para estimar cantidades e inferir relaciones causales a partir de datos.

Con esta doctrina, Pearson se acercó mucho a la conversión en campos técnicos (en el sentido presentado más arriba) de disciplinas como la antropología física, la psicología, la medicina, la sociología y la eugenesia. Si hemos de creer que Pearson reservaba para la estadística un lugar central en la esfera pública, no será fingiendo que proponía airearlo todo en los debates, o que dar vía libre a la discusión era la característica esencial de la sociedad democrática. A la manera de Condorcet, Pearson ansiaba elevar el tono de las polémicas y centrarlas en torno a la verdad para arrebatarlas de las manos de egoístas e ignorantes. Pensaba que una buena educación habría de familiarizar a los ciudadanos con el método científico, que desde su punto de vista, consistía en algo de metodología, cierta experiencia en un campo científico particular y una fuerte dosis de moralidad, entendida como imparcialidad desinteresada. Aunque los trabajadores y tenderos no iban a convertirse en expertos en estadística matemática, podían aprender a distinguir entre aquellos en quienes confiar y los charlatanes y vociferadores, y de éstos no faltaban. Pearson sospechaba de cualquier movimiento popular, por ejemplo, nunca se adhirió a la Eugenics Society y, cuando varias veces afirmó que ésta hacía cosas «en el nombre de la eugenesia», trataba de denunciar que mucho de lo que allí se hacía era vender gato por liebre. Y lo mismo pensaba de gran parte de la medicina, la economía o la biología, lo que le llevó a crudos enfrentamientos con médicos, economistas y biólogos.

Dado que la estadística matemática parece hacer explicito el razonamiento subjetivo - $-\mathrm{y}$, en cierto modo, hacerlo riguroso-, llama la atención que Pearson no confiara en la eficacia, siquiera pedagógica, de ningún tipo de receta. Se negaba a escribir o utilizar libros de texto, y en su lugar, proponía una combinación de lecciones magistrales e instrucción personal en su laboratorio de biometría. Este desapego a presentar los fundamentos de la estadística por escrito puede recordar a las técnicas utilizadas por los viejos gremios para mantener el privilegio del secreto y cerrar la puerta a los no iniciados. De hecho, Pearson escribió de modo laudatorio acerca de las universidades medievales y de los gremios y su dependencia de las relaciones directas y personales. Sin embargo, su rechazo de los libros de texto tenía más que ver con el lugar que, en la práctica científica, Pearson asignaba al saber hacer, la sabiduría y la moralidad personal.

Muestra de ello es la asociación que hacía entre ciencia y sabiduría, algo que parece poco plausible en nuestra época, pero que no era rara en 1900. Los famosos victorianos defensores del naturalismo científico, como Thomas H. Hux-

EMPIRIA. Revista de Metodología de Ciencias Sociales. N. ${ }^{\circ}$ 18, julio-diciembre, 2009, pp. 19-35. ISSN: 1139-5737 
ley, no aspiraban a derribar el viejo ideal de una elite sabia y capaz, sino a sustituir su instrucción literaria por una formación científica que ellos consideraban más afín al sentido común y el buen hacer. Creo que esta es la razón por la que Pearson dio el título de The Grammar of Science a sus conferencias públicas sobre asuntos científicos en el Gresham College y al libro que las recogió en 1892. «Gramática» quiere decir rudimentos, pero también alude al papel de las lenguas muertas en la educación tradicional del dirigente bien formado. Ese papel formador debía ahora corresponder a la estadística y las ciencias, pues la altura intelectual y moral del político y del científico no podía sustituirse por bibliotecas de información fáctica. Aunque Pearson no teorizó sobre la esfera pública, se esforzó durante toda su vida por incidir en ella. No consideraba que la ciencia (para él casi sinónimo de medida — metron - y cálculo) fuese incompatible con los foros de debate público y razonado, al contrario, su realización sólo sería posible de la mano de las ciencias. Sin duda, ésta era una visión idealizada del debate público que aparecía, ante todo, como racional, pero Pearson confiaba en que ese ideal se podía alcanzar, siempre que se introdujeran las debidas jerarquías en la estructura de las creencias y las discusiones populares.

Por esto mismo, no lo olvidemos, Pearson ayudó a consolidar una de las fuerzas tendentes al desmantelamiento de la esfera pública. No pretendo aquí, desde luego, defender sus posiciones políticas, pero sí me permito observar que Pearson provenía de un mundo casi desaparecido, en el cual aún era posible pensar que la ciencia nos haría sabios y buenos. Hoy, pocos de los que conozcan sus campañas públicas pensarán que Pearson era ejemplo de este vínculo, sobre todo si pensamos en la eugenesia y en las calumnias que amontonaba sobre cualquier estadístico que disintiera de su revista «Santa Biométrica». Para nuestro trabajo es clave señalar que sus ideales contenían una tensión profunda y crucial, una tensión que incluso alguno de sus contemporáneos percibió. Pearson daba por sentado que la ciencia podía ofrecer una perspectiva desinteresada en asuntos públicos controvertidos, que podía evitar exagerar la certeza de sus resultados y que sería reconocida el público, sin embargo, se frustraba constantemente ante la tozudez de sus colegas científicos, incluso (o, tal vez, especialmente) de los físicos que podían sobresalir en sus respectivos campos pero que parecían olvidar toda metodología científica cuando trataban de asuntos externos a ellos. Si no, ¿cómo es que tantos de ellos se habían dedicado a temas imposibles, tales como el estudio de los poderes mentales y el espiritismo? A esta tensión se añadía el hecho de que, para 1900, era cada vez más y más difícil para un científico ser capaz de engarzar con el público manteniendo el respeto de sus colegas.

Para Pearson, el manejo de la estadística era un gran aliado del método científico y, para muchos de sus admiradores, la eugenesia terminaba por completar el proyecto. Pearson dedicó tantos o más esfuerzos a las mediciones empíricas como a las matemáticas, y consideraba que los métodos estadísticos aportarían la perspectiva científica a casi cualquier problema relevante. A la par que luchaba por formar buenos estadísticos, no cejaba en el empeño de introducir la disciplina en los planes de estudios, de modo que cualquier persona edu-

EMPIRIA. Revista de Metodología de Ciencias Sociales. N. ${ }^{o}$ 18, julio-diciembre, 2009, pp. 19-35. ISSN: 1139-5737 
cada pudiese dominar el razonamiento estadístico. Es decir, se oponía a la segregación de los expertos en estadística respecto al resto de los ciudadanos, confiando en que las matemáticas elevarían el nivel del debate público sin necesidad de ignorarlo. Esta perspectiva se mantuvo con fuerza en las ciencias con relevancia política directa hasta principios del siglo veinte, y no llegó a desaparecer del campo de la estadística.

Y, sin embargo, ya entonces la estadística contribuía en mayor medida a presentar resultados envueltos en cajas negras que a fomentar el debate público o la comprensión de los resultados. R. A. Fisher (rival visceral de Pearson), contribuyó a empujar a la estadística todavía más en la dirección de las disciplinas técnicas tanto por lo intricado de sus matemáticas como por su insistencia en determinados métodos y herramientas. El test de significación estadística, que se extendió como la pólvora en las décadas de 1930 y 1940, era una técnica para separar el trigo de la paja, esto es, los resultados que podían verse como válidos, al menos provisionalmente, de los que habían de desecharse. Pero el patrón estadístico para semejante clasificación era puramente cuantitativo y no dejaba apenas resquicio a la consideración propia del asunto o del resultado obtenido ( $\mathrm{Zi}$ liak y McCloskey 2008). Estos métodos de Fisher (combinados con, o independientemente de, los que proponían Jerzy Neyman y el hijo de Pearson, Egon) fueron adoptados por muchas disciplinas, que los veían como el único camino, estrecho y sin atajos, para obtener resultados científicos válidos; la rutina que implicaban serviría de indicio para identificar a aquellos aptos para ser integrados en una comunidad investigadora. Podría objetarse que esto sólo puede aplicarse a la historia norteamericana, pero lo cierto es que tras las dos guerras mundiales, los Estados Unidos alcanzaron en el panorama científico internacional una posición capaz de hacer exportables dichos planteamientos. La nueva estadística va a operar con estándares de racionalidad muy rígidos, y con métodos que requerirán mucho entrenamiento y condiciones experimentales o de muestreo de un tipo particular.

Los científicos sociales del siglo pasado generalizaron la idea de que las sociedades modernas y complejas requieren técnicos expertos de alto nivel como los que ellos mismos ofrecían, puesto que el sentido común y la intuición no eran suficientes para abordar un terreno dibujado a escala de problemas económicos y sociales en los que intervienen multitud de factores aparentemente lejanos. Para comportarse de acuerdo con este ideal científico, tenían que demostrar su distancia de la mera opinión, empleando para ello métodos rigurosos que llevarían a conclusiones aceptables por sus colegas de profesión. Y, aun entonces, debían guardarse de compartir estas conclusiones con el público hasta que los especialistas hubieran alcanzado un acuerdo, pero, llegados a este punto ¿sería el gran público capaz de comprender? En una época de sociedad de masas y de conocimiento especializado y técnico, la racionalidad pública es casi inimaginable. Pero, ante esta situación, las ciencias sociales no se han limitado a volverse sobre sí mismas, invocando el 'conocer por conocer' o a trabajar sólo para el deleite de sus colegas. Antes bien, los expertos en estadística y en cien-

EMPIRIA. Revista de Metodología de Ciencias Sociales. N. ${ }^{\circ}$ 18, julio-diciembre, 2009, pp. 19-35. ISSN: 1139-5737 
cias sociales han conservado su función pública y han afianzado su credibilidad comunicando sus resultados a las agencias de las administraciones públicas, las cuales, a su vez, agradecen la legitimidad de esta ciencia rigurosa y 'objetiva'. La política democrática requiere una nueva presentación de la ciencia como actividad ostentosamente apolítica. La relación de las ciencias con la administración del Estado, algo que había tomado diversas formas a lo largo del tiempo, se funda ahora en una clara desvinculación del conocimiento con respecto a los lugares donde va a ser aplicado. El público ha perdido legitimidad como partícipe en la producción del conocimiento e, incluso, como audiencia digna para los nuevos resultados científicos que les afectan, lo cual no es óbice para que las voces de los grupos de interés se hagan oír en los procesos de toma de decisiones.

$\mathrm{Y}$, sin embargo, sería un error suponer que el discurso de la estadística ha pasado totalmente a manos de los expertos. Los resultados estadísticos del siglo XX atrajeron más atención que todos sus predecesores. Los famosos estudios de entreguerras como los de Middletown, los informes Kinsey sobre comportamiento sexual o las encuestas de opinión pública, atrajeron un enorme interés, como ha demostrado Sarah Igo (Igo 2007). Desde el punto de vista de la información pública, el desarrollo más interesante de la estadística desde 1900 puede cifrarse en el establecimiento de unos pocos indicadores que como iconos han venido a representar fenómenos tan complejos como la riqueza nacional, la salud y el bienestar, las condiciones laborales, los precios, el carácter de una población, el crimen, la desigualdad, la administración fiscal del Estado y, en general, lo que la sociedad opina sobre esto o lo otro. Tales indicadores se mantienen fieles al modelo de las ciencias de posguerra, productoras de descripciones austeras, delgadas, magras. La recogida de información no suele problematizarse y el cálculo de tasas e índices se considera un asunto técnico, interesante tan sólo para especialistas. Un público adecuadamente conformista debiera dejar de lado las preguntas difíciles y limitarse a dar fe de sí los indicadores presagian buenos o malos augurios, a decidir si esto refrenda o no determinadas políticas, o si los administradores elegidos o nombrados para los cargos son los adecuados o debieran ser sustituidos.

En efecto, a menudo el público acepta y asimila los indicadores de modo acrítico, pero también a menudo, surgen respuestas más complejas y activas. El esfuerzo, continuo desde finales del siglo diecinueve, por reducir los fenómenos sociales a unos pocos números, tales como el PIB, los indicadores de criminalidad, inflación, alfabetización, mortalidad infantil, etc., se ve constantemente contrariado por la existencia de indicadores alternativos para describir prácticamente las mismas cosas. Hay medias y hay medianas, ingresos por personas e ingresos por hogares, desempleados que reciben cheques de ayuda social y personas que se ven obligadas a realizar trabajos temporales o no cualificados, etc. De esta suerte, los partidarios de uno u otro bando en un debate pueden defender sus posiciones respectivas basándose en cifras que cambian según minúsculas variaciones en la definición de los indicadores oficiales. En estos casos, el proceso de empaquetar la información en cajas negras no fuerza el consenso,

EMPIRIA. Revista de Metodología de Ciencias Sociales. N. ${ }^{\circ}$ 18, julio-diciembre, 2009, pp. 19-35. ISSN: 1139-5737 
sino que, más bien, incrementa las dificultades de resolución de los debates.

Para los grupos directamente implicados, a menudo la recolección y cálculo de los datos pertinentes no permanecen ocultos. Probablemente la elaboración de un censo es la operación estadística más pública puesto que, normalmente, como mínimo un miembro de cada unidad familiar deberá rellenar un formulario con preguntas diseñadas por el científico social, y podrá, por tanto, imaginar que el resto del censo es el resultado, simplificando, de la repetición varios millones de veces de su propio acto de responder al formulario. Muchos procedimientos administrativos colaboran en la construcción de tablas de indicadores, como acontece en las aduanas, partes de inmigración, juzgados y prisiones o escuelas y hospitales. Otras cifras son de un interés acuciante para las comunidades a las que van referidas, incluso hay ocasiones en las que un dato no ocasiona protestas cuando va referido a la población entera y, sin embargo, la disociación de sus partes puede tener consecuencias ideológicas o financieras de peso: anglicanos y disidentes católicos en la Gran Bretaña de 1851, las subdivisiones de Canadá en los censos de mediados del siglo diecinueve, población judía y Palestina en Israel, sin techo e inmigrantes ilegales en las ciudades norteamericanas, etc. En estos casos, es frecuente ver como los afectados pugnan por cuadrar sus propias cuentas (Wolfenstein 2004; Curtis 2001; Leibler y Beslau 2005) Emmanuel Didier ha descrito una sucesión de intentos de hacer estimaciones y medidas de las cosechas que van desde principios del siglo veinte hasta la Segunda Guerra Mundial, pasando por la Gran Depresión, que incluían la preocupación por encontrar informantes creíbles o por configurar mecanismos de medida adecuados; cada uno de estos intentos se nutría, y ejercía, diversas concepciones del orden político democrático (Didier 2009).

La relación de los consumidores con la obtención de las estadísticas de precios es menos directa y, sin embargo, los resultados pueden afectarles de modo inmediato, por lo que no siempre son aceptados de forma pasiva. De hecho, los consumidores han invocado su propia experiencia como compradores de comida o ropa, comparadores de casas o usuarios de vehículos, para argumentar que el indicador no es bueno, o que no recoge su situación particular como familia con hijos de ciertas edades, en determinada clase social y en una ciudad o barrio determinado. Thomas Stapleford demuestra que, en los Estados Unidos, tales objeciones a las medidas oficiales de precios alcanzaron una considerable amplitud ya en la década de 1920. El propio índice para el coste de la vida depende de la compresión, en un solo número, de una gran heterogeneidad de productos y circunstancias. La historia de Stapleford documenta la lucha por deshacer este agregado por parte de la acción colectiva de diferentes tipos de gente. No es simplemente una crónica de lo fútil, puesto que las protestas públicas han determinado en ocasiones cambios de método, pero el indicador ha sobrevivido para ser destruido una y otra vez con objeto de establecer mediante el cálculo lo que resulta demasiado complejo y controvertido para la política (Stapleford 2009).

Carecería de justificación sostener que los métodos técnicos estadísticos, o la ciencia en general, han clausurado todo debate público o que han logrado des- 
vincularse totalmente de la intervención y el debate políticos. Más bien, lo que han hecho es determinar la reformulación de la esfera pública y asumir funciones destacadas en los discursos políticos del mundo contemporáneo. El poder de los números surge de la aplicación de estándares uniformes, 'objetivos', aparentemente independientes de presiones políticas y aderezados con un toque de 'abracadabra' que asegura que los resultados de los cálculos satisfagan cierto grado de aceptabilidad práctica y política. La razón estadística ofrece un faro hacia una racionalidad impersonal lograda por métodos técnicos y, sin embargo, se transforma una y otra vez, por la alquimia de la política contemporánea, en un elemento retórico y de lucha entre instituciones y grupos de interés.

\section{BIBLIOGRAFÍA}

AldER, Ken. 2002. The Measure of All Things. New York: Free Press.

Anderson, Margo J. 1988. The American Census: A Social History (New Haven: Yale University Press).

BAKER, Keith M. 1975. Condorcet: From Natural Philosophy to Social Mathematics (Chicago: University of Chicago Press).

BRIAN, Eric. 1994. La mesure de l'état: Administrateurs et géomètres au XVIIIe siècle. Paris: Albin Michel.

Cullen, M. J. 1975. The Statistical Movement in Early Victorian Britain: The Foundations of Empirical Social Research (Hassocks, Sussex: Harvester Press).

CurTIs, Bruce. 2001. The Politics of Population: State Formation, Statistics, and the Census of Canada, 1840-1875 (Toronto: University of Toronto Press).

DAston, Lorraine and Peter Galison. 2007. Objectivity (New York: Zone Books).

DESROSIÈres, Alain. 1993. La politique des grands nombres: Histoire de la raison statistique (Paris : La Découverte).

DIDIER, Emmanuel. 2009. En quoi consiste l'amérique?: les Statistiques, le new deal, et la démocratie (Paris: La Découverte).

EZRAHI, Yaron. 2002. «Science and the Political Imagination in Contemporary Democracies», in Sheila Jasanoff, ed., States of Knowledge: The Co-Production of Science and Social Order (New York: Routledge), 254-273.

GigerenZer, Gerd, et al. 1989. The Empire of Chance: How Probability Changed Science and Everyday Life (Cambridge: Cambridge University Press).

GILlisPIE, Charles C. 1980. Science and Polity at the End of the Old Regime (Princeton: Princeton University Press).

GILlisPIE, Charles C. 2004. Science and Polity in France: The Revolutionary and Napoleonic Years. Princeton: Princeton University Press.

Goldman, Lawrence. Science, Reform, and Politics in Victorian Britain: The Social Science Association, 1857-1886 (Cambridge: Cambridge University Press)

HABERMAS, Jürgen. [1962 ] 1989. The Structural Transformation of the Public Sphere: An Inquiry into a Category of Bourgeois Society (Cambridge: Polity).

HaCKING, Ian. 1990. The Taming of Chance (Cambridge: Cambridge University Press).

HANEY, David Paul. 2008. The Americanization of Social Science: Intellectuals and Public Responsibility in the Postwar United States. Philadelphia: Temple University Press.

EMPIRIA. Revista de Metodología de Ciencias Sociales. N. ${ }^{\circ}$ 18, julio-diciembre, 2009, pp. 19-35. ISSN: 1139-5737 


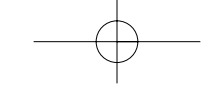

HASKELL, Thomas. 1977. The Emergence of Professional Social Science (Urbana: University of Illinois Press).

HigGs, Edward. 2004. The Information State in England (Houndmills, Basingstoke, Hampshire: Palgrave Macmillan).

HILTS, Victor. 1978. «Aliis Exterendum, or, the Origins of the Statistical Society of London», Isis, 69, 21-43.

Himmelfarb, Gertrude. 1991) Poverty and Compassion: The Moral Imagination of the Late Victorians (New York: Alfred A. Knopf).

HORKHEIMER, Max and Theodor W. ADORNO. [1944] 1972. The Dialectic of Enlightenment: Philosophical Fragments (New York: Continuum).

Igo, Sarah. 2007. The Averaged American: Surveys, Citizens, and the Making of a Mass Public (Cambridge: Harvard University Press).

LABBÉ, Morgane. 2007. «Institutionalizing the Statistics of Nationality in Prussia in the $19^{\text {th }}$ Century (from local bureaucracy to state-level census of population)», Centaurus, 49, 289-306.

LeIBLER, Anat and Daniel Breslau. 2005. 'The Uncounted: Citizenship and Exclusion in the Israeli Census of 1948,' Ethnic and Racial Studies, 28, 880-902.

LiNDENFELD, David. 1997. The Practical Imagination: The German Sciences of State in the Nineteenth Century (Chicago: University of Chicago Press).

PALSKY, Gilles. 1996. Des chiffres et des cartes: Naissance et développement de la cartographi quantitative française au XIXe siècle (Paris: Comité des travaux historiques et scientifiques).

PATRIARCA, Silvana. 1996. Numbers and Nationhood: Writing Statistics in NineteenthCentury Italy (Cambridge: Cambridge University Press).

Pick, Daniel. 1989. Faces of Degeneration: A European Disorder, c. 1848-1918 (Cambridge: Cambridge University Press).

PORTER, Theodore M. 1986. The Rise of Statistical Thinking, 1820-1900 (Princeton: Princeton University Press).

PORTER, Theodore M. 1995. Trust in Numbers: The Pursuit of Objectivity in Science and Public Life. Princeton: Princeton University Press.

PORTER, Theodore M. 2003. «The Social Sciences», in David Cahan, ed., From Natural Philosophy to the Sciences: Writing the History of Nineteenth-Century Science (Chicago: University of Chicago Press), 254-290.

Porter, Theodore M. 2004. Karl Pearson: The Scientific Life in a Statistical Age (Princeton: Princeton University Press).

PorTER, Theodore M. 2006. «Speaking Precision to Power: The Modern Political Role of Social Science», Social Research, 73, 1273-1294.

PORTER, Theodore M. 2009. «How Science Became Technical», Isis, 100 No 2 (June): 292-309.

PORTER, Theodore M. «Reforming Vision: The Engineer Le Play Learns to Observe Society Sagely», in Lorraine Daston and Elizabeth Lunbeck, eds., Histories of Scientific Observation (Chicago: University of Chicago Press, en prensa).

RusNock, Andrea. 2002. Vital Accounts : Quantifying Health and Population in Eighteenth-Century England and France (Cambridge: Cambridge University Press).

StAPLEFord, Thomas A. 2009. The Cost of Living in America: A Political History of Economic Statistics, 1880-2000 (Cambridge: Cambridge University Press).

Stigler, Stephen M. 1999. Statistics on the Table: The History of Statistical Concepts and Methods (Cambridge: Harvard University Press).

EMPIRIA. Revista de Metodología de Ciencias Sociales. N. ${ }^{\circ}$ 18, julio-diciembre, 2009, pp. 19-35. ISSN: 1139-5737 
SzReter, Simon. 1996. Fertility, Class, and Gender in Britain, 186-1940 (Cambridge: Cambridge University Press).

Topalov, Christian. 1994. Naissance du chômeur, 1880-1910. Paris: Albin Michel.

WolfensteIn, Gabriel K. 2004. Public Numbers and the Victorian State: The General Register Office, the Census, and Statistics in Nineteenth-Century Britain (Ph.D. Dissertation: University of California, Los Angeles).

ZILIAK, Stephen T. and Deirdre N. MCCloskey. 2008. The Cult of Statistical Significance (Ann Arbor: University of Michigan Press).

\title{
RESUMEN
}

La estadística, en su forma matemática, jugó un papel importante en la transformación de las ciencias sociales en campos técnicos cuya aspiración de objetividad suponía que la ciencia social debía apartarse del conocimiento común y del razonar ordinario. Este ideal, que creció en el siglo XX y especialmente en las décadas alrededor de 1950, configuró de nuevo las relaciones de la ciencia (incluyendo la ciencia social) con las culturas que la nutrieron. La ciencia social estadística del siglo XIX, a pesar de su alianza con la administración del estado, valoró el compromiso público por encima de la disciplina de la imparcialidad. La elaboración de nuevos ideales de cuantificación fue asistido, por tanto, por una redefinición de la razón pública.

\section{PALABRAS CLAVE}

Racionalización, estadística, tecnificación de las ciencias, razón pública, objetividad

\begin{abstract}
Statistics in its mathematical form played a key role in making the social sciences into technical fields, whose claim to objectivity presumed that social science should stand apart from common knowledge and ordinary reasoning. This ideal, which grew up in the twentieth century and especially in the decades around 1950, reconfigured the relations of science (including social science) to the cultures that nurtured it. Statistical social science in the nineteenth-century, though allied to state administration, valued public engagement over disciplined detachment. The elaboration of new ideals of quantification was thus attended by a redefinition of public reason.
\end{abstract}

\section{KEYWORDS}

Rationalization, statistics, techinicality (in science), public reason, objectivity 